\section{Sciona and genetic testing}

$W^{\text {e were disappointed in the tenor of }}$ your recent editorial ${ }^{1}$. Our goal is the translation of genetics research and technology into services and products that benefit patients and consumers. We agree with the thoughts expressed by Ledley ${ }^{2}$ that "radical reassessment of healthcare delivery models is necessary to ensure that the health benefits of genomics are realized by the greatest number of individuals in the shortest possible time".

We help achieve this aim by the simple expedient of helping people to help themselves by optimizing their nutrition. Poor nutrition is a major health issue. Simple steps to optimize nutrition can have profound effects on overall health status in the population. There are agreed principles of nutrition ${ }^{3}$ and a sound scientific basis for the role of nutrients and metabolic enzymes in diet (the latter being encoded by the genes that form the basis of Sciona's tests). The impact of genetic variation on the functionality of these enzymes has been extensively studied (see http://www. Sciona.com for further reading).
The size and robust nature of geneticnutritional interactions are well documented in the literature. The meta analysis of Wald et al. ${ }^{4}$ indicates that "lowering homocysteine concentrations by 3 $\mu \mathrm{mol} \mathrm{l^{-1 }}$ from current levels (achievable by increasing folic acid intake) would reduce the risk of ischemic heart disease by $16 \%$ ( 11 to $20 \%$ ), deep vein thrombosis by $25 \%$ ( 8 to $38 \%$ ) and stroke by $24 \%$ ( 15 to $33 \%)$ ". The link between genetic variation in MTHFR and folic acid metabolism has been exhaustively documented ${ }^{5,6}$. Other reviews also conclude that "characterization of such gene polymorphisms will enable targeting of nutritional advice and treatment to 'at risk' groups"7.

We link the dietary practices of a consumer with their genetic profile to produce advice aimed at the individual (Body Benefits $^{\mathrm{TM}}$ ), highlighting the specific things to pay attention to from the grand sweep of best nutritional practice. You also raise concerns about the impact of results on those being tested. The feedback from our customers is positive. People appreciate the specific advice-they wish to know how they can act to help themselves optimize their nutrition as part of their larger desire to improve their health and well-being.

In conducting our business, we have consulted widely with regulatory bodies, ethicists both in Europe and the US, technologists and scientists. Our service reflects these attempts to match best practice and meet concerns regarding privacy and data security. We expect the latter will form a substantial piece of the conceptual infrastructure that will be critical for the delivery of personalized medicine, commonly regarded and predicted as being one of the primary benefits of the Human Genome Project.

\section{Gareth Roberts \& Keith Grimaldi}

Sciona Ltd., 25 Broadmarsh Innovation Centre, Harts Farm Way, Havant, Hampshire PO9 1HS, UK. Correspondence should be addressed to K.G. (e-mail: keith.grimaldi@sciona.com).

1. Editorial. Nat. Genet. 32, 553-554 (2002).

2. Ledley, F. Nat. Biotechnol. 20, 767 (2002).

3. Garrows, J.S., James, W.P.T. \& Ralph, A. Human Nutrition and Dietetics edn. 10 (Churchill Livingstone, London, 2000).

4. Wald, D.S et al. Br. Med. J. 325, 1202-1206 (2002).

5. Fohr, I.P. et al. Am. J. Clin. Nutr. 75, 275-282 (2002).

6. Ashfield-Watt, P.A. et al. Am. J. Clin. Nutr. 76, 180-186 (2002).

7. Elliott, R. \& Ong T.J. Br. Med. J. 324, 1438-1442 (2002). 